\title{
Preschoolers iPad Supported Task Design for EFL Learning. Key Features in Design
}

\author{
Nathaly Gonzalez-Acevedo
}

\begin{abstract}
The use of technology in the classroom has been a request of society to pedagogy in the recent years and consequently an increasing research focus on technology-supported language learning and teaching has aroused. The research around preschooler's language learning and teaching supported by technology is of much interest to pedagogy as it focuses on the foundation stage. This paper explores key features of iPad-supported language learning task designs for preschoolers. The methodology employed to identify salient features in the design of tasks is an action research of three cycles of action implemented in two mixed gender groups of seven preschoolers. The objective of the analysis of the task design being thus of promoting meaningful English as foreign language leaning through adequate task designs supported by technology. The data analyzed makes salient some features in the effective design of tasks such as collaboration orientation, autonomous group work orientation, collaborative use of iPad and collaborative product presentation. The study identifies meaningful features in the EFL learning in autonomous and collaboratively iPad supported task designs and indicates the close relation of technology-supported tasks with the teaching and learning of key twenty first century skills.
\end{abstract}

Index Terms-Collaborative tasks, EFL, iPad, preschoolers, task design.

\section{INTRODUCTION}

The use of technology in the classroom has been a request of society to pedagogy in recent years and consequently an increasing research focus on technology-supported language learning and teaching has aroused. The rapidly growing insertion of technology in society has changed the way people communicate and use technology. In this line, Prensky [1]-[3], argues that recent generations should be consider as digital natives as they have grown in a society that is highly mediated by technology. Research around students' learning orientation highlights that children are no longer happy with being mere receptors of knowledge but that they want to be active participants [4]. Such argument, elaborates on the idea that students are oriented to learning through technology and in a multimodal way. It has been argued that scholars needed to focus their attention in the new literacies [5] and acknowledge the multimodal literacies present in classrooms

Manuscript received January 10, 2018; revised May 1, 2018. The author has received the support of the project 'Knowledge for Network-based Education, Cognition \& Teaching (KONECT)' financed by the Ministerio de Economía y Competitividad: Proyectos I+D del Programa Estatal de Fomento de la Investigación Ciéntifica y Técnica de Excelencia (EDU2013-43932-P).

Nathaly Gonzalez-Acevedo is with the GREIP Consolidated Research Group, Universitat Autònoma de Barcelona, 08193 Bellaterra, Barcelona, Spain (e-mail: nathaly.gonzalez@uab.cat). and daily lives. It has been long argued that research and pedagogy need to acknowledge that different modes are present in today's communication [5].

In the same line, the embeddedness of technology in communication, information seeking, and society production and consumption cannot be ignored. Some scholars highlight how excessive quantity and accessibility to information can be infoxicating [6] and how this should be covered by education as a key skill. Others state that education should not only focus on information seeking but on efficiently create a society of consumers and producers of information on prosumers [7].

In this line, more recent studies and research around technology have argued that digital skills should not be regarded as $21^{\text {st }}$ Century Skills but as part of a broader picture. In this sense, pedagogy is now advocating for a more holistic approach to technology and its actual and future uses [8]-[12]. The International Society for Technology Education outlines, six principles to approach technology; creativity and innovation; communication and collaboration; research and information fluency; critical thinking, problem solving and decision making; digital citizenship and technology operations and concepts. Such broader understanding of the role of technology in society is in line with the affordances of technology and the reclamations of society to technology.

In this paper, technology is understood in its broader sense. The use of technology in a task design does not only answer to the use of a learning support but as the catapult to work $21^{\text {st }}$ Century Skills in the classroom of English as Foreign Language, exploring key features of iPad-supported language learning task designs for preschoolers which not only focus on digital skills and concepts but in a technology competence [13]-[15].

\section{METHODOLOGY}

The methodology employed in this research is an action research of three cycles of implementation. An action research is a research that is based on an extensive literature review but informed and reformulated through the research by the own action. Action research methodology is a very much used approach in education.

In the research at hand the researcher designed an iPad supported language learning task based on extensive literature review on technology teaching and learning in preschool based on previous documented experiences [8].

The research was carried out in a private school in Barcelona in which English is taught as the instruction language although it is a foreign language for the majority of the students and for all the participants in the research. The 
students mother tongue is Catalan or Spanish and they are all bilingual. The research was implemented in one preschool group of 5 to 6 year olds in two mixed-gender groups of seven children that were chosen given to accessibility. The two groups were stable during the research that lasted around 6 months.

The role of the researcher was thus of a teacher-researcher [16] conferring the study ethnographic insight. Hence the researcher, was not an outsider in the group and her presence can be recognized as blended in the context of teaching and learning.

The task was designed to develop English language skills, specifically phonetic skills. The aim was to design a task in which children had to work on the correspondence of letters and sounds and on the identification of letter-sounds in the beginning position of a word. Thus, children were given a set of letters, which they related to their phonetic sound, and were asked to compile a book of sounds by adding, for each letter, the picture of an object beginning with each letter sound. The total letter-sounds given to the children were 26 and children were familiar with them although not all of them were capable of recognizing each letter or matching it with its corresponding sound. The language learning objectives were to consolidate letter sound correspondence and English vocabulary.

The analysis of the task deign was documented by the researcher during the implementation. The researcher maintained a detailed follow up of the evolution of the intervention using field notes and a collection of approximately 60 hours of video recordings. The data used for this paper are the field notes and the field diary of the researcher in which the practice modification was based on. Hence, this paper is the description of the evolution of the intervention as it was annotated and recorded by the researcher. The analysis of the cycles of interventions is supported by the video data that corroborates the points considered.

\section{ANALYSIS}

The action research was implemented through three cycles of action. Each cycle was informed by previous action and reformulated to accomplish a task design creation of a language learning task that not only incorporating language learning objectives but $21^{\text {st }}$ Century Skills.

\section{A. First Cycle of Action}

During the first cycle of action preschoolers were given a set of 7 letters in a session of 60 minutes. Each child had an iPad and was responsible for modeling one letter with plasticine and take a picture of the plasticine letter and use such picture as a background to draw digitally, on the iPad, an object beginning with the letter assigned. The app used for the task was Doodle, which is an intuitive app that allows taking pictures and using various drawing tools to draw on the picture as can be seen in Fig. 1. The children worked in a small group and were aided by the classroom assistant.

The classroom assistant aided the children with technology issues such as taking the picture, uploading the picture to the app, solving app errors as well as language related aid such as giving word examples for the letters. The assistant was in charge of the task management and therefore had the control over time and task final product (e.g. accepting preschoolers' production). The assistant was thus in charge of technical support, language support and task management, children were responsible of modeling the plasticine letter and producing the digital page containing a picture of the plasticine model and a drawing of an object beginning by that letter.

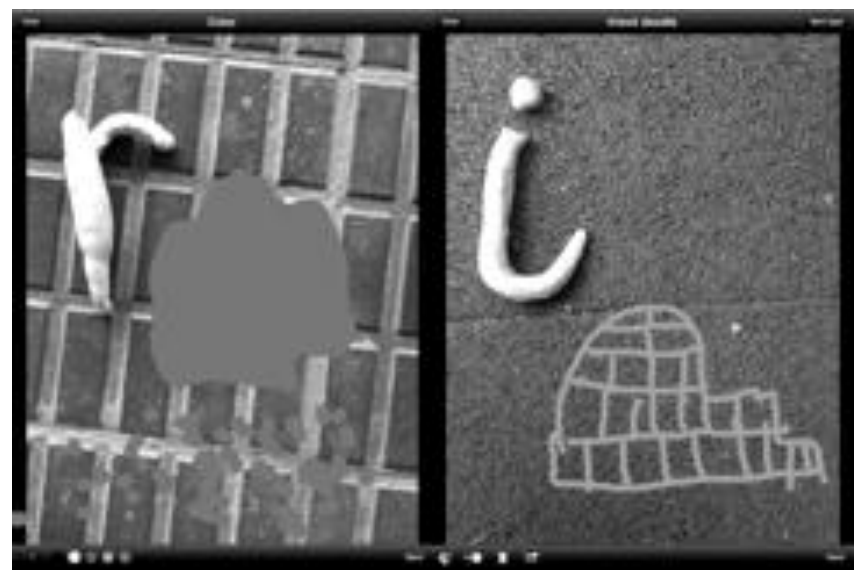

Fig. 1. Example of final product of letters $r$ (rain) and I (igloo).

The task lasted 4 sessions to cover all the letters and the final product was a power point presentation in which all the doodle pages were exported and attached to the presentation in order to create the book of letters. The teacher carried out the exportation and formatting of the power point presentation. The preschoolers watched the power point presentation as final collaborative product.

\section{B. Analysis -First Cycle of Action}

The first cycle aimed to use technology as a productivity tool. After the first cycle, some considerations were taken into account to design an informed second cycle aiming to improve the 21st Century Skills developed through the task.

As for the task design the following points were considered

1) Preschoolers needed the aid of the adult to solve technical problems, including issues related to the affordances of the app, the navigation on the iPad and the use of the camera.

2) There was low collaboration during and through the creation process. The collaboration was based on the recollection of individual work to be used as a compilation.

3) High sense of authorship, preschoolers recognized their page as own and failed to feel the completed work as a collaborative work product.

4) Each preschooler had a personal pace and those finishing first disengaged from the task.

The points made salient after the analysis of the first cycle of action derived in a redesign of the task in order to solve counterproductive agency of the adult as technical support and the low collaboration and low sense of group belonging.

\section{Second Cycle of Action}

During the second cycle of action the preschoolers were given the same set of letters but the teacher assistant aid was removed. Each student was given an iPad and the set of letters 
was displayed on the work space. Preschoolers were expected to organize themselves as to choose the letter each one was going to illustrate during the task. The main direction given to the students was that the set of 7 letters had to be finished during the 60 minutes session and that the task was autonomous as the adult was not going to be present during the process.

The complete set of 26 letters was produced in 4 sessions. During the sessions the preschoolers were in charge of solving technical problems, manage who was illustrating which sound and agreeing on such decisions as well as being responsible for the completion of the 7 sounds during the sessions. The same app, doodle, was used and the instruction was the same; a plasticine model of the letter; a picture of the plasticine model and an illustration of an object beginning with that letter. The groups were maintained.

The task lasted 4 sessions and the final product was not presented as power point presentation. Not all letters were presented as some students failed to present their letter.

\section{Analysis -Second Cycle of Action}

During the second cycle of implementation the design made visible that removing the technical support of the adult previously considered as key, in the use of technology in preschool, was not an obstacle for the completion of the task. All the technological obstacles encountered by the preschoolers were efficiently overcome without much of adult's help.

As for the task design the following points were considered:

Autonomous work created a space in which preschoolers helped each other, making use of previous technology knowledge, to overcome technology difficulties and iPad navigation issues.

The group worked collaboratively and such collaboration constructed a sense of belonging to the group that was visible by the way in which the preschoolers oriented to their work as one and not as a sum of individual works. However, collaboration was still a weak point.

The need of a space of free choice, in which preschoolers iPad's use was not designed by the task was noticed as needed. Preschoolers made explicit their need to have free time to play with iPad as a recreational tool and not as a productivity tool.

Some conducts highlighted the importance of covering aspects such as ethical behavior. It was noted that preschoolers were ready to unders and that having an iPad was not a license to take pictures of others without their permission.

\section{E. Third Cycle of Action}

During the third cycle of implementation the task design aimed at covering different $21^{\text {st }}$ Century Skills as part of the task goals. The objectives were to develop collaboration, critical thinking skills, problem solving skills, decision making skills and technology operations and concepts.

For the last cycle of intervention, the cycles oriented the researcher to choose an app supporting different modes.Thus, the app used during this cycle was My Story as it supported audio recording, stickers, digital drawing while offering the resemblance to a digital book in which the final product could be exported as a video including all the modes included in the created pages.

The main modification to the initial task design was to give each group just $1 \mathrm{iPad}$ to work on the set of letters. The group was given the complete set of letters, not just 1 for each participant, and given just 1 iPad to share.

The app was new to the students and was roughly introduced, only the main features such as how to create a book and add pages to an existing book and how recordings were included was introduced. Features such as using drawing tools or stickers was not presented.

The initial instruction given required students to complete the 26-letter set during a 60 minutes session. The two groups needed 4 sessions to complete the task. Task management, technical support and language support was relegated to the students.

The final product was a book containing 26 letter-sounds including, for each letter-sound, a traced letter and the representation (sticker or digital drawing) of an object beginning with that sound-letter. The book had to follow the order given, which corresponded to the order in which they are presented to children.

\section{F. Analysis -Third Cycle of Action}

The third cycle aimed at developing $21^{\text {st }}$ Century Skills through a task designed to work language content. The introduction of a new app for the task did not seem to be an obstacle, Fig 3 is an example of a very similar product than Fig 1 and 2 realized during cycle 3 , the preschoolers were able to discover different tools that the app offered and managed to organize themselves to use just $1 \mathrm{iPad}$ and tackle all the letter-sounds.

It can be observed that collaboration was meaningfully exploited by creating a task in which the preschoolers had to share the productivity tool, the iPad, Preschoolers did not argue significantly about the use of the It can be observed that iPad, they managed to share the tool once the letter-sound auto-assigned was considered finished by the author itself.

As for the task design all the following aspects were considered:

The request of help from the adult was significantly low. And where there was help requested was not related to technical support but behavior management.

The task management was highly efficient, the preschoolers that were not in charge of the iPad were managing time and showing a clear orientation towards the task completion.

Preschoolers stayed on task during the session and maintained psychically as a group in the same work space. There was some on-off task orientation but there were always an orientation towards the task completion.

Preschoolers worked autonomously, they did not need the attention of the teacher or assistant and in those cases in which assistance was needed one member of the group fetched the helped while the rest of the members stayed in the work space.

Salient examples of critical-thinking, problem-solving and decision-making were visible.

Preschoolers final product was perceived as a sole project done in collaboration, the completion of the task was celebrated as a group achievement. 


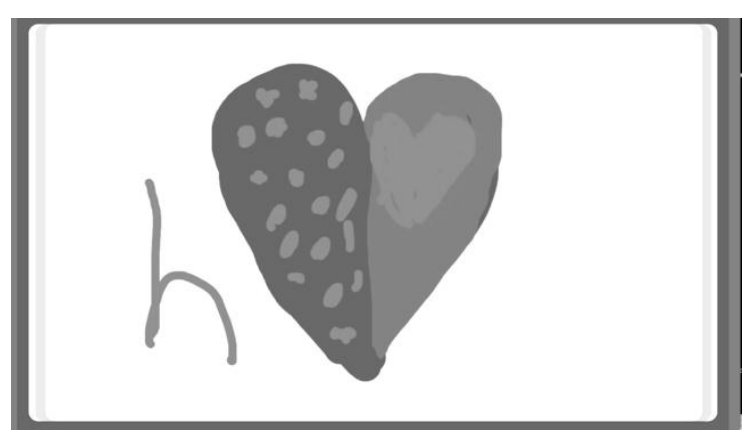

Fig. 2. Example of final product of letters h (heart) using My Story.

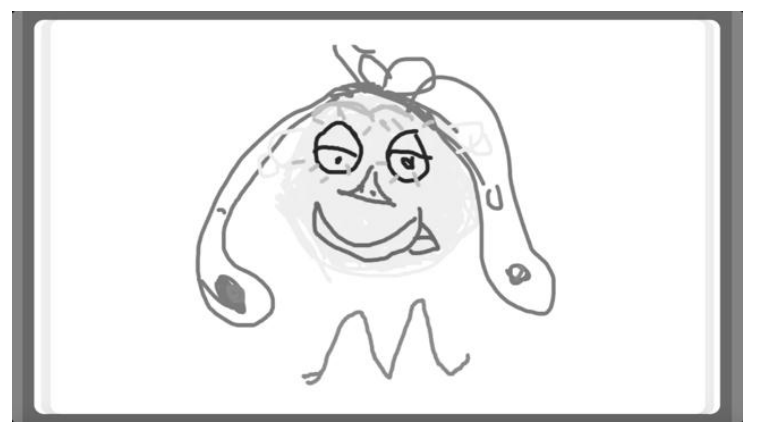

Fig. 3. Example of final product of letter m (mum) using My Story. 1

\section{CONCLUSION}

This paper addresses task designs as working spaces that can create meaningful interaction and learning in preschool settings. It has been seen how through the informed modification of the task the preschoolers' agency has been recognized and as a consequence the task has offered to the preschoolers spaces in which $21^{\text {st }}$ Century Skills are worked.

The action research implementation and data collection makes salient some features in the effective design of tasks such as collaboration orientation, autonomous group work orientation, collaborative use of iPad and collaborative product presentation. This paper identifies meaningful features in the EFL learning in autonomous and collaboratively iPad supported task designs. It is argued that autonomous tasks are well accepted by preschoolers and that they are capable of working autonomously. On the other hand, collaboration at such young ages presents a challenge that motivate students to finish the task and work collaboratively as a group.

The last cycle of action presents and autonomous and collaborative iPad supported task and indicates the close relation of technology-supported tasks with the teaching and learning of key $21^{\text {st }}$ Century Skills.

As a conclusion it can be argued that preschoolers age and maturity level should not be a drawback when designing iPad supported tasks. It has been seen how preschoolers benefit more from autonomous and collaborative work spaces than through constant adult guidance.

Future research, around the data collected is focused on language learning triggers and task management triggers during autonomous and collaboratively iPad supported tasks. The evidence here presented points to highly rich interaction of preschoolers during autonomous and collaboratively task.

Furthermore, the use of free play supported by iPads and digital ethical values education are salient points that need to be further studied.

\section{ACKNOWLEDGMENT}

The researcher would like to thank the preschoolers involved in the project for their dynamic spirit and their parents for granting permission for the research to take place. This research would not have been possible without the parents' and the school's principal confidence in the researcher. The assistant was a person during the research and her insight gave much support to the field notes.

\section{REFERENCES}

[1] M. Prensky, "Digital natives, digital immigrants part 1," On the horizon, vol. 9, no. 5, pp.1-6, 2001.

[2] M. Prensky, "Digital natives, digital immigrants part 2," On the Horizon, vol.9, no. 5, pp. 1-6, 2001.

[3] M. Prensky, "H. sapiens digital: From digital immigrants and digital natives to digital wisdom," Innovate: Journal of Online Education, vol.5, no. 3, 2009.

[4] B. Cope and M. Kalantzis, "“Multiliteracies": New literacies, new learning." Pedagogies: An International Journal, vol. 4, no.3, pp. 164-195, 2009.

[5] The New London Group, "A pedagogy of multiliteracies: Designing social futures," Harvard educational review. vol. 66, no. 1, pp. 60-93 1996.

[6] E. Benito-Ruiz. "Infoxication 2.0." Handbook of Research on Web 2.0 and Second Language Learning, IGI Global, pp. 60-79, 2009.

[7] P. Kotler. "The prosumer movement: A new challenge for marketers," ACR North American Advances, 1986.

[8] J. Lynch, and T. Redpath, “"Smart” technologies in early years literacy education: A meta-narrative of paradigmatic tensions in iPad use in an Australian preparatory classroom," Journal of Early Childhood Literacy, vol. 14, no. 2, pp.147-74, 2014.

[9] C. Lankshear, and M. Knobel, "New technologies in early childhood literacy research: A review of research," Journal of Early Childhood. vol. 3, no.1, pp. 59-82, 2003.

[10] K. Wohlwend, "Early adopters: Playing new literacies and pretending new technologies in print-centric classrooms," Journal of Early Childhood Literacy, vol. 9, no 2, pp. 117-140, 2009.

[11] S. Hill, "The millennium generation: Exploring new forms of literacy," Journal Early Childhood Literacy, vol. 10, no. 3, pp. 314.-340, 2010.

[12] O'Mara and L. Laidlaw, "Living in the iWorld: Two literacy researchers reflect on the changing texts and literacy practices of childhood," English Teaching: Practice and Critique, vol.10, no. 4, pp.149-159, 2011

[13] G. Falloon and E Khoo, "Exploring young students' talk in iPad-supported collaborative learning environments," Computers and Education, vol. 77, pp. 13-28, 2014.

[14] R. Flewit, D. Messer, and N. Kurcikova, "New directions for early literacy in a digital play: The iPad," Journal of Early Childhood Literacy, pp. 1-22, 2014.

[15] C. Jewitt, "Multimodality, 'reading' and 'writing' for the $21 \mathrm{st}$ century'." Discourse, vol. 26, no. 3, pp. 315-331, 2005

[16] A. Konstantinos. "Being a teacher| researcher: A primer on doing authentic inquiry research on teaching and learning," Springer, 2015.

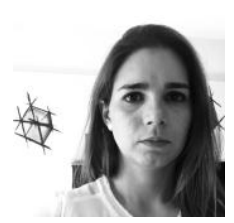

Nathaly Gonzalez-Acevedo has a Teacher degree mention in English as foreign language, 2010, Universitat de Barcelona, Barcelona. Master's degree in research in language and literature teaching methodology, 2012 Universitat Autònoma de Barcelona, Barcelona. Master's degree in Research in Education, 2014, by the UAB and it is actually a PhD

candidate at the UAB

She is a full-time preschool teacher and a part-time teaching assistant at $\mathrm{UAB}$. She is interested in very young learners' agency and in task designs to support and develop agency. She is interested in social semiotic multimodal analysis. She is interested in technology in education and language learning in preschool. 